() Р. Б. Гевко, д.т.н., С. З. Залуцький, к.т.н.

Тернопільський національний технічний університет ім. Івана Пулюя

О. М. Троханяк, к.т.н.

Національний університет біоресурсів і природокористування України

С. В. Синій, к.т.н.

Луцький національний технічний університет

\title{
ДОСЛІДЖЕННЯ ПАРАМЕТРІВ ВЗАЄМОДІЇ ЗЕРНОВОГО МАТЕРІАЛУ ІЗ ПОВЕРХНЕЮ ЕЛАСТИЧНОЇ СЕКЦІЇ ШНЕКА
}

У статті запропоновано нову конструкиію шнека 3 секиійною еластичною поверхнею, яка призначена для зменшення ступеня пошкодження зернового матеріалу при його транспортуванні. Проведено теоретичний розрахунок взаємодіі зернини з еластичною секиією шнека. Наведено результати експериментальних досліджень.

ГНУЧКИЙ ГВИНТОВИЙ КОНВЕЕР, ЗЕРНОВИЙ МАТЕРІАЛ, ЕЛАСТИЧНА СЕКЦІЯ ШНЕКА, ТЕОРЕТИЧНІ РОЗРАХУНКИ, БАГАТОФАКТОРНИЙ ЕКСПЕРИМЕНТ

Постановка проблеми. Шнекові конвеєри отримали широке використання під час транспортування сільськогосподарських матеріалів. Однак при їх переміщенні виникає значне пошкодження транспортованих тіл, що відбувається внаслідок попадання частинок у зазор між поверхнею обертання шнека та нерухомою внутрішньою поверхнею кожуха, що також призводить до підвищення енерговитрат.

Проблема зниження пошкодження зернових матеріалів при їх транспортуванні шнековими робочими органами, незважаючи на значну кількість досліджень, які пов'язані 3 визначенням оптимальних параметрів гвинтових робочих органів, $є$ не повністю вирішеною. Суттєвого зменшення пошкодження сільськогосподарських матеріалів при їх транспортуванні можна досягнути шляхом застосування еластичних поверхонь робочих органів, що дозволить мінімізувати пошкодження та енергоємність технологічного процесу.

Аналіз останніх досліджень і публікацій. Вирішенню даних питань, а саме розробці енергоощадних конструкцій 
гвинтових робочих органів та вибору їх раціональних параметрів $\mathrm{i}$ режимів роботи присвячені праці [1-7].

Результати досліджень контактної взаємодії зерна 3 робочими поверхнями, а також напрямки підвищення ресурсу роботи гвинтових транспортерів викладено в роботах $[8,9]$.

В науковій літературі та патентах на винаходи дедалі частіше зустрічаються конструктивні рішення, які спрямовані на більш кардинальне вирішення даних проблемних питань, в першу чергу за рахунок застосування на робочих поверхнях еластичних елементів. Теоретичні дослідження в даному напрямі наведено в роботах $[10,11]$.

Мета дослідження. Метою даних досліджень $є$ зниження ступеня пошкодження сипких матеріалів шляхом використання розробленої конструкції шнека з секційною еластичною гвинтовою поверхнею та визначення його раціональних параметрів.

Результати дослідження. Для зниження ступеня пошкодження зернового матеріалу при його транспортуванні шнековими робочими органами пропонується до жорсткої гвинтової основи кріпити еластичні секції, які повинні прогинатись у випадку попадання зернин у зазор, що утворений між нерухомою внутрішньою поверхнею направляючого кожуха та обертовою периферійною поверхнею шнека [12]. При визначенні зусиль, які виникають при безпосередній взаємодії еластичного ребра шнека, в якості зернового матеріалу розглянемо зернину кукурудзи, форму якої можна описати півсферою з переходом у конус [13, 14].

Розглянемо процес взаємодії еластичної секції шнека (рис. 1) iз напівсферичною поверхнею зернини кукурудзи 1, яка защемлена між внутрішньою поверхнею направляючого кожуха 2 та периферійною поверхнею еластичної секції 3.

Положення зернини кукурудзи, яка може бути найбільш ймовірно защемленою зображено на рис. 1.

При защемленні зернина кукурудзи своєю конусною поверхнею торкається внутрішньої поверхні кожуха, а сферичною поверхнею взаємодіє з еластичною секцією шнека.

Защемлення зернини відбувається у випадку, коли максимальний початковий кут $\alpha_{n}$ між нормальною силою взаємодії еластичного ребра шнека 3 поверхнею зернини $N_{b}$ і площиною, перпендикулярною до осі обертання шнека, $є$ меншим ніж кут тертя зернини по внутрішній поверхні направляючого кожуха.

При защемленій зернині еластична секція ковзає відносно неї в коловому та осьовому напрямках з відповідною деформацією. Напрямок сили $N_{b}$ при цьому наближається до осі $O Y$, а її величина 
зростає. Теоретичні розрахунки спрямовані на визначення таких параметрів взаємодії еластичної секції із зерниною, при яких буде виключена можливість іiі пошкодження. Тобто еластична секція шнека прогнеться відносно защемленої зернини не пошкоджуючи іiі.

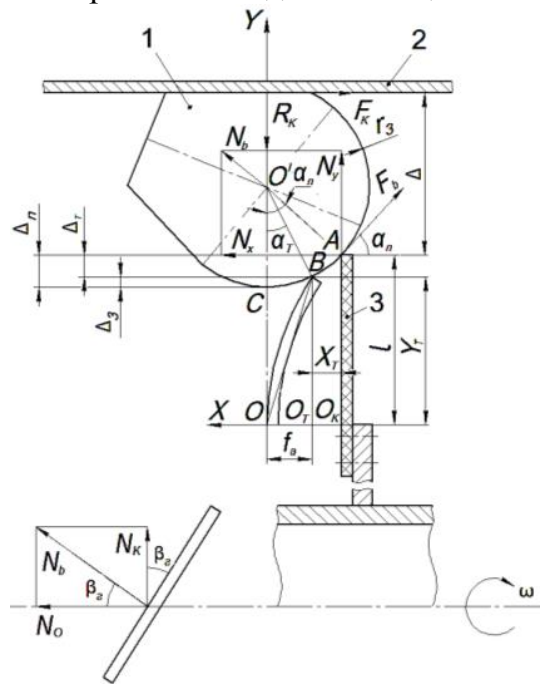

Рис. 1 - Схема зусиль, переміщень та деформацій, які виникають між еластичною секцією шнека та защемленою зерниною кукурудзи

Розглянемо процес переміщення еластичної секції від початку їі контакту із зерниною (точка $A$ ), який визначається кутом $\alpha_{T}$ до певного поточного розташування (точка $B$ ). Оскільки еластична секція шнека не $є$ абсолютно пружною, а величина iï прогину $\epsilon$ незначною, то в першому наближенні приймемо, що довжина хорди $O B$ дорівнює довжині консольної частини еластичної секції $l$.

Попередньо визначимо висоту еластичної секції у здеформованому стані $V_{T}$ при переміщенні її вільного кінця з т. $A$ в т. $B$, тобто від початкового кута контакту $\alpha_{n}$ до поточного $\alpha_{T}$. Тоді

$$
y_{T}=l-\Delta_{T}
$$

де $\Delta_{T}$ - величина поточного зазору між еластичною секцією та внутрішньою поверхнею кожуха, м, визначається з виразу

$$
\Delta_{T}=\Delta_{n}-\Delta_{3},
$$

де $\Delta_{n}$ та $\Delta_{3}-$ відповідно величини початкового та залишкового перекриття еластичної секції із зерниною, м.

Величини $\Delta_{n}$ i $\Delta_{3}$ відповідно визначаються:

$$
\begin{aligned}
& \Delta_{n}=r_{3}-r_{3} \cos \alpha_{n}=r_{3}\left(1-\cos \alpha_{n}\right), \\
& \Delta_{3}=r_{3}-r_{3} \cos \alpha_{T}=r_{3}\left(1-\cos \alpha_{T}\right),
\end{aligned}
$$


де $r_{3}$ - радіус напівсферичної поверхні зернини кукурудзи, м.

Підставляючи залежності (3) і (4) у (2) матимемо:

$\Delta_{T}=r_{3}\left(1-\cos \alpha_{n}\right)-r_{3}\left(1-\cos \alpha_{T}\right)=r_{3}\left(\cos \alpha_{T}-\cos \alpha_{n}\right)$.

Підставляючи (5) в (1) отримаємо:

$$
y_{T}=l-r_{3}\left(\cos \alpha_{T}-\cos \alpha_{n}\right) \text {. }
$$

Тоді 3 трикутника $B O O_{T}$ визначаємо поточне значення прогину еластичної секції:

$$
f_{a}=\sqrt{l_{a}^{2}=l^{2}-Y_{T}^{2},}
$$

Після перетворень отримаємо

$$
f_{a}=\sqrt{r_{3}\left(\cos \alpha_{T}-\cos \alpha_{n}\right)\left(2 l-r_{3}\left[\cos \alpha_{T}-\cos \alpha_{n}\right]\right)} \text {. }
$$

Згідно [15] переміщення навантаженого кінця консольно закріпленої балки визначається за формулою:

$$
f_{a}=\frac{N l^{3}}{3 E I} k \text {. }
$$

де $N$ - сила взаємодії еластичної секції з поверхнею зернини, $\mathrm{H}$;

$E$ - модуль пружності еластичної секції, Па;

$I$ - момент інерції еластичної секції, м $^{4}$;

$k$ - коефіцієнт, який враховує форму профілю еластичної секції шнека.

Підставляючи $f_{a} 3$ рівняння (8) в рівняння (9), а також враховуючи момент інерції секції, матимемо силу $N_{b}$, яка виникає між периферією еластичної секції та зерниною за залежністю:

$$
N_{b}=\frac{E\left(b^{4}-a^{4}\right) \sqrt{r_{3}\left(\cos \alpha_{T}-\cos \alpha_{n}\right)\left(2 l-r_{3}\left[\cos \alpha_{T}-\cos \alpha_{n}\right]\right)}}{16 l^{2}(b-a) k} .
$$

Згідно даних [15] модуль пружності для цих матеріалів становить: гума (при малих деформаціях): $E=(0,01 \ldots 0,1) \cdot 10^{9}$ Па; поліетилен низького тиску: $E=0,2 \cdot 10^{9}$ Па; поліетилен високого тиску: $E=0,8 \cdot 10^{9}$ Па.

Приймемо, що аналіз залежності (10) будемо проводити в діапазоні значень $E=(0,05 \ldots 0,25) 10^{9}$ Па, при середньому значенні $E=0,15 \cdot 10^{9}$ Па. Величину консольного виступу еластичної секції змінювали в межах $l=0,024 \ldots 0,032$ м, при середньому значенні $l=0,028$ м. Значення $b$ та $a$ приймали в межах: $b=0,020 \ldots 0,024$ м; $a=0,014 \ldots 0,018 \mathrm{M}$.

Згідно відомих досліджень [5] довжина зернини кукурудзи знаходиться в межах 0,0052..0,014 м; ширина - 0,005...0,011 м; товщина - 0,003...0,008 м. Тому радіус iї півсферичної поверхні 
приймали в межах $r_{3}=0,0015 \ldots 0,0045$ м (середнє значення $\left.r_{3}=0,003 \mathrm{M}\right)$.

При визначенні інтенсивності впливу вищезазначених параметрів на величину $N_{b}$ прийнято крайнє значення $\alpha_{T}=0^{\circ}$. Відповідно у формулі (10) величина $\cos \alpha_{T}=1$.

Тоді залежність (10) прийме вигляд:

$$
N_{b}=\frac{E\left(b^{4}-a^{4}\right) \sqrt{r_{3}\left(1-\cos \alpha_{n}\right)\left(2 l-r_{3}\left[1-\cos \alpha_{n}\right]\right)}}{16 l^{2}(b-a) k} .
$$

Сила $N_{b}$, яка діє перпендикулярно до площини ребра розкладається на осьову $N_{o}$, що діє в напрямку осі шнека і колову $N_{\kappa}$, яка діє в його поперечному перерізі.

Осьова та колова сили відповідно приймуть вигляд:

$$
\begin{gathered}
N_{o}=\frac{E\left(b^{4}-a^{4}\right) \sqrt{r_{3}\left(1-\cos \alpha_{n}\right)\left(2 l-r_{3}\left[1-\cos \alpha_{n}\right]\right)}}{16 l^{2}(b-a) k} \cos \beta_{2} ; \\
N_{k}=\frac{E\left(b^{4}-a^{4}\right) \sqrt{r_{3}\left(1-\cos \alpha_{n}\right)\left(2 l-r_{3}\left[1-\cos \alpha_{n}\right]\right)}}{16 l^{2}(b-a) k} \sin \beta_{2} .
\end{gathered}
$$

Встановлено, що максимальний вплив на значення $N_{o}$ i $N_{k}$ має модуль пружності гвинтової поверхні еластичної секції. Далі за інтенсивністю впливу на величину $N_{o} \in \alpha_{n}$, довжина консольного виступу ребра шнека $l$ та кут $\beta_{2}$ нахилу гвинтової поверхні еластичної секції.

Для проведення експериментальних досліджень розроблений еластичний шнек 3 перекриттям сусідніх еластичних секцій [15], конструктивна схема якого зображена на рис.2. Він містить центральний вал 13 жорсткою основою 2, до якої за допомогою гвинтових пластин 4 та болтів 3 напівкруглими головками 5 та гайок 6 кріпляться еластичні секції 3. При транспортування сипких матеріалів в кожусі 7, при попаданні зернин між поверхнею кожуха та еластичних секцій, останні прогинаються, що знижує пошкодження зернин. 


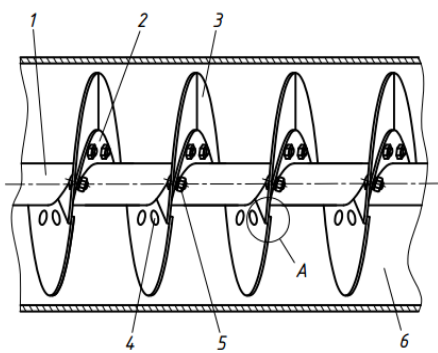

a
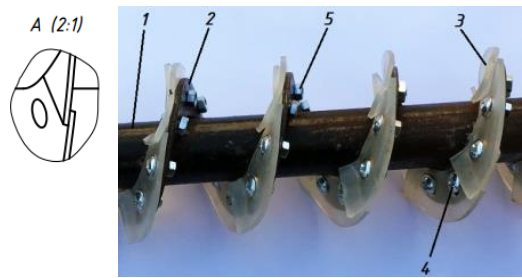

6

Рис. 2 - Конструктивна схема (а) та загальний вигляд (б) шнека 3 перекриттям еластичних секцій

Розроблено експериментальну установку гвинтового конвеєра, яка зображена на рис. 3 [12].
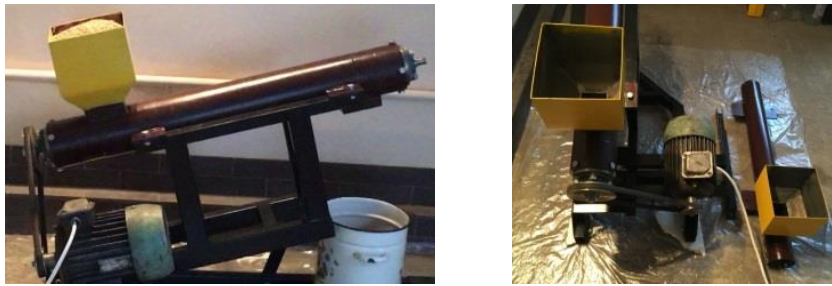

Рис. 3 - Експериментальна установка для проведення досліджень секційних еластичних шнекових робочих органів

За результатами експериментальних досліджень визначено енерговитрати на привід гвинтового конвєра 3 секційною еластичною робочою поверхнею при транспортуванні зернового матеріалу та отримано рівняння регресії

$$
\begin{array}{r}
P=0,055+0,11 \cdot 10^{-2} n-0,06 \cdot 10^{-4} \alpha-0,014 \Delta+0,21 \cdot 10^{-5} n \alpha+ \\
40,84 \cdot 10^{-4} n \Delta+0,75 \cdot 10^{-4} \alpha \Delta-0,33 \cdot 10^{-6} n^{2}+0,21 \cdot 10^{-4} \alpha^{2}-0,5 \cdot 10^{-4} \Delta^{2} .
\end{array}
$$

Поверхні відгуку, які побудовані на основі рівняння регресії (14) зображені на рис. 4. 3 їх аналізу встановлено, що домінуючим фактором, який впливає на величину $P \in$ частота $n$. Далі за інтенсивністю впливу є кут $\alpha$ та величина зазору $\Delta$. 


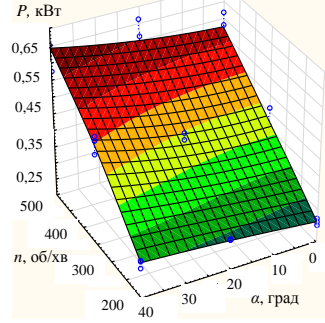

a

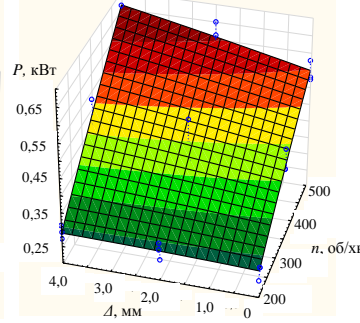

6

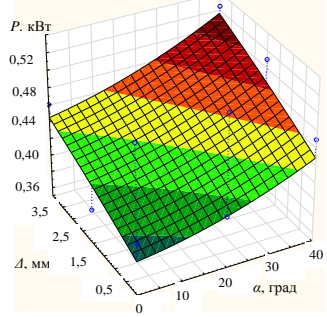

B

Рис. 4 - Поверхні відгуку залежності потужності $P$ на привод конвеєра:

$$
\begin{gathered}
\mathrm{a}-P=f(n, \alpha) \text { при } \Delta=2 \text { мм; б }-P=f(\Delta, n) \text { при } \alpha=20 \text { град.; } \\
\text { в }-P=f(\Delta, \alpha) \text { при } n=350 \text { об/хв }
\end{gathered}
$$

Проведені дослідження з визначення ступеня травмування зернового матеріалу шнеком жорстким $T_{\text {ж }}$ та еластичним $T_{e}$.

Для жорсткого шнека рівняння регресії залежності ступеня травмування зернового матеріалу від $\alpha, n$ і $\Delta$ має вигляд

$$
T_{\varkappa}=0,0108+0,0046 \alpha+0,0005 n+0,053 \Delta .
$$

Для еластичного шнека рівняння регресії залежності ступеня травмування зернового матеріалу від $\alpha, n$ i $\Delta$ має вигляд

$$
T_{e}=0,0011+0,0012 \alpha+0,0002 n+0,051 \Delta .
$$

Відповідні поверхні відгуку від зміни факторів для жорсткого шнека $T_{\text {ж }}$ зображено на рис. 5 , а для еластичного шнека $T_{e}$ - на рис. 6.

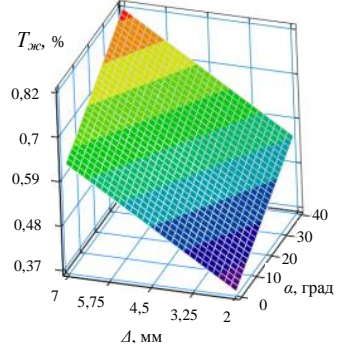

a

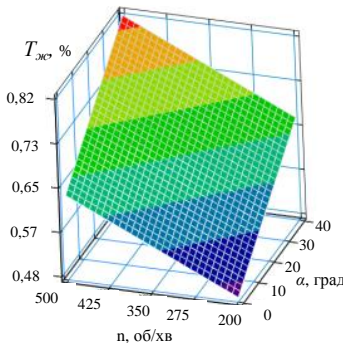

6

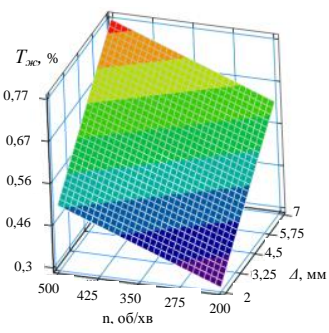

B

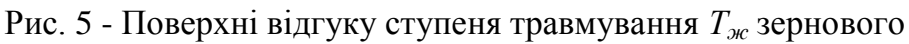
матеріалу жорстким шнеком від зміни двох факторів:

$$
\mathrm{a}-T_{\varkappa}=f(\Delta, \alpha) ; \sigma-T_{\varkappa}=f(n, \alpha) ; \text { в - } T_{\varkappa}=f(n, \Delta)
$$




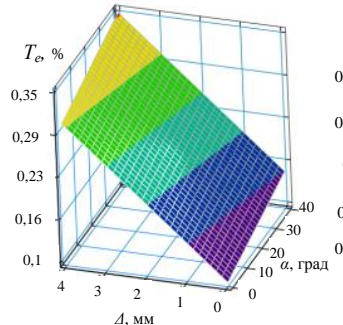

a

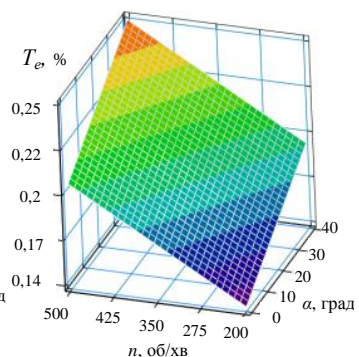

6

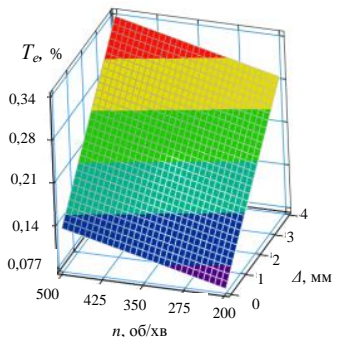

B

Рис. 6 - Поверхні відгуку ступеня травмування $T_{e}$ зернового матеріалу еластичним шнеком від зміни двох факторів:

$$
\text { а }-T_{e}=f(\Delta, \alpha) ; \sigma-T_{e}=f(n, \alpha) ; \text { в }-T_{e}=f(n, \Delta)
$$

3 аналізу поверхонь відгуку встановлено, що домінуючим фактором, який впливає на значення $T_{\text {ж}}, \epsilon$ величина зазору $\Delta$. Далі за інтенсивністю впливу є кут $\alpha$ і несуттєво поступається йому за впливом частота обертання робочого органу $n$.

Висновки. На основі виведених аналітичних залежностей обгрунтовано раціональні параметри взаємодії еластичних секцій із зерновим матеріалом форми півсфера-конус. Визначено інтенсивність впливу параметрів взаємодії еластичної секції шнека та зернини кукурудзи на величини осьової $N_{o}$ та колової $N_{k}$ сил. Встановлено, що максимальний вплив на значення $N_{o}$ i $N_{k}$ має модуль пружності еластичної секції шнека. Далі за інтенсивністю впливу на величину $N_{o} є$ початковий кут взаємодії еластичного ребра шнека 3 поверхнею зернини, довжина консольного виступу еластичної гвинтової секції та їі кут нахилу.

Наведено результати експериментальних досліджень та встановлено межі рекомендованих параметрів.

\section{Література}

1. Baranovsky V. M., Hevko R. B., Dzyura V. O., Klendii O. M., Klendii M. B., Romanovsky R. M. Justification of rational parameters of a pneumoconveyor screw feeder // INMATEH: Agricultural engineering, vol.54, no.1., , 2018, pp. 15-24, Bucharest, Romania.

2. Бойко А.І., Куликівський В.Л. Дослідження контактної взаємодії зерна в зазорі “виток-кожук” шнекових живильників зерноочисних машин // Науковий вісник НУБіПУ. - К. : Ред-вид. відділ НУБіПУ, 2011. - Вип. 166. Техніка та енергетика АПК. С. 267-274. 
3. Гевко Р. Б. Підвищення технічного рівня гнучких гвинтових конвеєрів : монографія / Р. Б. Гевко, А. О. Вітровий, А. І. Пік. - Тернопіль : Астон, 2012. - 204 с.

4. Гевко Р. Б. Підвищення технологічного рівня процесів завантаження та перевантаження матеріалів у гвинтових конвеєрах: монографія / Р.Б. Гевко, Р.М. Рогатинський, Р.І. Розум, М.Б. Клендій та ін. - Тернопіль: Осадца Ю.В., 2018. - 180 с.

5. Hevko R.B., Zalutskyi S.Z., Tkachenko I.G., Klendiy O.M. (2015) - Development and investigation of reciprocating screw with flexible helical surface // INMATEH: Agricultural engineering, vol.46, no.2, 2015, pp. 33-138, Bucharest, Romania.

6. Hevko R.B., Yazlyuk B.O., Liubin M.V., Tokarchuk O.A., Klendii O.M., Pankiv V.R. Feasibility study of mixture transportation and stirring process in continuous-flow conveyors, // INMATEH: Agricultural engineering, vol.51, no.1, 2017, pp.49-59, Bucharest, Romania.

7. Hevko R.B., Strishenets O.M., Lyashuk O.L., Tkachenko I.G., Klendii O.M., Dzyura V.O. Development of a pneumatic screw conveyor design and substantiation of its parameters, / INMATEH: Agricultural engineering, vol.54, no.1, 2018, pp.153-160, Bucharest, Romania.

8. Ловейкін В., Рогатинська Л. Модель транспортування сипкого вантажу швидкохідними гвинтовими конвеєрами 3 еластичними робочими органами // Вісник ТНТУ ім. І. Пулюя, вип. 16, 2011, Тернопіль, С. 66-70.

9. Lyashuk O.L., Rogatynska O.R., Serilko D.L. Modelling of the vertical screw conveyer loading // INMATEH Agricultural Engineering, vol.45, no.1, 2015, pp.87-94, Bucharest, Romania.

10. Lyashuk O.L., Sokil M.B., Klendiy V.M., Skyba O.P., Tretiakov O.L., Slobodian L.M., Slobodian N.O. Mathematical model of bending vibrations of a horizontal feeder-mixer along the flow of grain mixture // INMATEH Agricultural Engineering, vol.55, no.2, 2018, pp.35-44, Bucharest, Romania.

11. Manjula E.V.P.J., Hiromi W.K. Ariyaratne, Ratnayake Chandana, Morten C. Melaaen A review of CFD modelling studies on pneumatic conveying and challenges in modelling offshore drill cuttings transport // Powder Technology, Vol.305, 2017, pp.782-793.

12. Гевко Р.Б. Розробка конструкції шнека 3 еластичною гвинтовою поверхнею та результати іiі експериментальних досліджень / Р.Б. Гевко, С.З. Залуцький // Вісник інженерної академії України. - К. : 2015. - № 1. - С. 242-247. 
13. Залуцький С.З., Гевко Р.Б., Гладьо Ю.Б., Ткаченко І.Г., Клендій О.М. Рух потоку сипкого матеріалу по поверхні шнека 3 еластичними секціями, що перекриваються між собою // Харківський національний технічний університет сільського господарства імені Петра Василенка, вип.11, Харків, 2018, С.81-90.

14. Hevko R.B., Zalutskyi S.Z., Hladyo Y.B., Tkachenko I.G., Lyashuk O.L., Pavlova O.M., Pohrishchuk B.V., Trokhaniak O.M., Dobizha N.V. Determination of interaction parameters and grain material flow motion on screw conveyor elastic section surface // INMATEH Agricultural Engineering, vol.57, no.1, 2019, pp.123-134, Bucharest, Romania.

15. Писаренко Г.С., Яковлев А.П., Матвеев В.В. Справочник по сопротивлению материалов // Наукова думка, Київ, 1988, 736 с. 